\title{
Hepatic necroinflammation and severe liver fibrosis in patients with chronic hepatitis B with undetectable HBV DNA and persistently normal alanine aminotransferase
}

\author{
Alam MM ${ }^{1}$, Mahtab MA ${ }^{1}, \mathrm{Akbar} \mathrm{SMF}^{2}$, Kamal M⿻ ${ }^{3}$, Rahman $\mathrm{S}^{1}$ \\ ${ }^{I}$ Department of Hepatology, Bangabandhu Sheikh Mujib Medical University, Shahbag, Dhaka, Bangladesh, \\ ${ }^{2}$ Department of Medical Sciences, Toshiba General Hospital, Tokyo, Japan, ${ }^{3}$ Department of Pathology, \\ Bangabandhu Sheikh Mujib Medical University, Dhaka, Bangladesh. \\ Email: shwapnil@agni.com
}

\begin{abstract}
Both consensus and controversy remains regarding surrogacy of hepatitis B virus (HBV) deoxyribonucleic acid (DNA) and alanine aminotransferase (ALT), however, these markers are used to ascertain the extent of liver damages and to guide therapeutic options in patients with chronic hepatitis B. However, little is known about liver histology of patients with chronic hepatitis B with undetectable HBV DNA and persistently normal ALT. Thirty-five incidentally-detected patients with chronic HBV infection (assessed by expression of hepatitis B surface antigen for more than 6 months) with undetectable HBV DNA and normal serum ALT were enrolled in this study. Liver biopsy specimens were taken from all patients and the extent of hepatic necroinflammation and liver fibrosis were evaluated. Moderate degree of hepatic necroinflammation was detected in 2 of 35 patients and severe hepatic fibrosis was seen in 6 of 35 patients. Two patients with undetectable HBV DNA and sustained normal ALT had moderate hepatic necroinflammation and severe hepatic fibrosis. In spite of undetectable HBV DNA for prolonged period and persistently normal ALT, some patients with chronic hepatitis B express evidences of progressive liver diseases. Large scale studies in different races and geographical regions should be accomplished to develop insights about management of these patients. Studies about extent of liver diseases in these patients should be accomplished in Treatment recommendation and management strategies should be developed for these patients.
\end{abstract}

\section{Introduction}

There are both consensus and controversy regarding real implication of serum levels of hepatitis $\mathrm{B}$ virus (HBV) DNA for diagnosis and treatment of liver damages in patients with chronic hepatitis B. ${ }^{1-7}$ It is well documented that during the natural history of chronic $\mathrm{HBV}$ infection, the risk for cirrhosis increases significantly with increasing HBV DNA levels and are independent of hepatitis $\mathrm{B}$ e-antigen status and serum alanine aminotransferase (ALT) level. ${ }^{1}$ Also, increased HBV DNA load (serum HBV DNA $>10^{5}$ copies $/ \mathrm{ml}$ ) is strongly associated with increased hepatocellular carcinoma and liver-related mortality after accounting for baseline cirrhosis, hepatitis B e antigen status, and ALT levels. ${ }^{2}$ These observations led to develop therapeutic recommendation for patients with chronic hepatitis B on the basis of serum titers of HBV DNA and ALT. Antiviral therapy is usually recommended for patients with chronic hepatitis B with HBV DNA > $10^{5}$ copies/ml and serum ALT levels of more than upper levels of normal (ULN). ${ }^{8-10}$
However, studies have also shown that patients with chronic hepatitis B with persistently low HBV DNA and persistently normal ALT may have considerable levels of liver damages. Even, some of them patients had liver cirrhosis when liver biopsy specimens of these patients were evaluated. ${ }^{4-7}$ However, there are paucity of information about the extent of liver damages in patients with undetectable HBV DNA and persistently normal ALT. These studies have not been accomplished as these patients are regarded as inactive HBV carrier. They are not indicated for any treatment. In addition, 3 eminent professional liver organizations of the world such as The American Association for the Study of Liver Diseases (AASLD), the European Association for the Study of the Liver (EASL), and the Asian-Pacific Association for the Study of the Liver (APASL) do not recommend a liver biopsy for these patients. ${ }^{8-10}$

Recently, we encountered some patients with chronic HBV infection. They expressed hepatitis B surface antigen (HBsAg) for more than 6 months. HBsAg positivity was detected as a chance finding 
during their visit to medical clinics for causes other than liver problems. Considerable numbers of these patients had serum ALT within upper limit of normal (ULN). HBV DNA was undetectable in their sera (estimation limit $<250$ copies/ml). They were $\mathrm{HBeAg}$-negative. They also do not have any subjective complains. According to management recommendations of AASLD, EASL, and APASL, they were recommended to have regular follow up. However, some of them developed acute on chronic liver failure or hepatic decompensation in future. It was assumed that understandings of extent of liver damages of these patients during first diagnosis of chronic HBV infection may yield proper insights about the pathological status of these patients.

In this study, liver biopsy specimens of a group of chronic $\mathrm{HBV}$-infected patients with undetectable HBV DNA, persistently normal ALT, and HBeAgnegative were checked. The data shows that some of these patients had considerable levels of hepatic necroinflammation and fibrosis. The outcome of this study would be discussed in the context of management of these patients. Also, public health implications of these patients in developing and resource-constrained countries seem to be immense.

\section{Materials and Methods}

The patients were selected from a pool of about 600 patients, who were apparently healthy without any features of liver-related diseases when they first visited the hospital. They came to the hospital for testing of serum HBsAg (1) before traveling to a foreign country for work (compulsory requirement to obtain a working visa for most developed countries), (2) on the advice of their physician because of pregnancy, (3) before receiving $\mathrm{HBV}$ vaccine or (4) before donating blood for transfusion. The study was conducted between July 2008 and June 2010.

The patients expressing $\mathrm{HBsAg}$ had a second HBsAg estimation 6 months after first hospital visit. When HBsAg was also detected 6 months after the first test, the patients were regarded as being chronically infected with HBV. HBV DNA was measured in all patents and also liver function test was evaluated to assess the extent of liver damages. Ultrasonography was also used to develop insights about chronic liver diseases.

Primary inclusion criteria for the study included: (1) positive for $\mathrm{HBsAg}$, twice at an interval of 6 months; (2) negative for serological markers of hepatitis $\mathrm{C}$ virus, $\operatorname{IgM}$ antibodies to hepatitis $\mathrm{A}$ virus and hepatitis E virus; (3) alcohol consumption of $<20 \mathrm{~g} /$ day (most Bangladeshis consume almost no alcohol for religious reasons); 4) age more than 18 years, and (5) no evidence of pregnancy. Among these, patients with undetectable HBV DNA (HBV DNA titer less than 250 copies/ml) in two successive assessments, alanine aminotransferase (ALT) below ULN (42 U/l), negative for hepatitis $\mathrm{B}$ e antigen (HBeAg) were enrolled in the final study. The numbers of patients were 35 . None of the patients received any antiviral drugs (treatmentnaïve) or immune modulators for treatment of $\mathrm{HBV}$ infection. A review board of "Viral Hepatitis Foundation, Bangladesh' provided permission to accomplish the study. The nature and purpose of the study were explained to all patients. Informed and written consent were taken from all patients. Patients were excluded from further analyses if adequate amounts of liver tissue were not available during liver biopsy, as recommended. ${ }^{11}$

\section{Biochemical and serological tests}

Levels of ALT in serum were measured commercially. The cutoff for the ULN of ALT was $>42 \mathrm{U} / \mathrm{l}$. HBeAg was checked using an ELISA kit (Abbott Labs, Chicago, IL, USA).

\section{Quantification of serum HBV DNA levels}

Serum HBV DNA was quantified using an RT-PCR kit (Amplicon HBV Monitor Assay, Roche Molecular Systems, CA, USA). The lower limit of detection was 250 copies of HBV DNA/ml.

\section{Liver biopsy}

A percutaneous liver biopsy was performed in all patients with prior, voluntary, informed written consent. Biopsies were performed under local anesthesia using a 16G Tru-cut biopsy needle (Cardinal Health, McGaw Park, IL, USA). A biopsy specimen of more than $1.0 \mathrm{~cm}$ in length with five to six portal tracts was evaluated. Histology was graded according to the histologic activity index (HAI) using the criteria of Knodell et al. ${ }^{12}$ The total HAI score comprises necroinflammation (HAI-NI) and fibrosis (HAI-F) scores. The HAI-NI scale includes three components (0-10, piecemeal necrosis; 0-4, lobular necrosis and inflammation; 0-4, portal inflammation). HAI-F was graded according to severity: 0, absence of fibrosis; 1 , fibrous portal expansion; 3, bridging fibrosis; 4, cirrhosis.

\section{Statistical analyses:}

Data are expressed as mean \pm standard deviation (SD). Data were analyzed by unpaired $t$ test if they were normally distributed and by Mann-Whitney rank-sum test if they were skewed. Differences were considered significant at $p<0.05$. 


\section{Results}

The age of the patients varied from 18 years to 40 years $(27.6 \pm 6.6$ years, mean and standard deviation). Twenty-eight patients were male and 7 were female. All patients were expressing HBsAg for more than 6 months, but were negative for $\mathrm{HBV}$ DNA in the sera (HBV DNA $<250$ copies/ml) for more than 1 year, had persistently normal ALT for more than 1 year (at least 3 assessments were done within 1 year). The levels of aspartate aminotransferase and prothormbin time were also within normal range in all patients (Table I). All were negative for $\mathrm{HBeAg}$ in the sera (Table I). Ultrasonography of the upper abdomen also did not reveal evidences of chronic liver diseases.

Table I: Demographic, clinical, biochemical and virological features of the patients

\begin{tabular}{lc}
\hline Parameters & $\begin{array}{c}\text { Patients } \\
\text { characteristics }\end{array}$ \\
\hline Numbers of patients & 35 \\
Age (mean and standard deviation) & $27.63 \pm 6.58$ years \\
Age (range) & $20-29$ years \\
Male & $28(80 \%)$ \\
Female & $7(20 \%)$ \\
Alanine aminotransferase (ALT) (Normal range: & $30.42 \pm 6.835$ \\
<42IU/L) & \\
Aspartate aminotransferase (AST) (Normal range & $31.43 \pm 6.446$ \\
<40IU/L) & $13.58 \pm 1.24$ \\
Prothrombin time (Normal range up to 16seconds) & $245 \pm 62.702$ \\
Platelet counts (150,000-250,000 /ml3) & 35 \\
Hepatitis B surface positive & 0 \\
Hepatitis B antigen positive & 35 \\
Hepatitis B e antibody positive & Negative (below \\
HBV DNA in sera & 250 copies/ml) \\
\hline
\end{tabular}

The extent of necroinflammation and hepatic fibrosis in liver biopsy specimens have been shown in Table II. Two of the 35 patients had moderate degrees of hepatic necroinflammation (HAI-N1 score: 9-12). On the other hand, severe fibrosis of HAI-F3 grade was detected in 6 patients. Out of 6 patients with severe hepatic fibrosis, 2 had moderate degree of hepatic necroinflammation. None of the patients had any subjective symptoms of liver diseases.

Table II: Histological findings of patients with chronic hepatitis B with undetectable HBV DNA and persistently normal alanine aminotransferase

\begin{tabular}{lc}
\hline Levels of necroinflammation (HAI N1 score) & $\begin{array}{c}\text { Numbers of } \\
\text { patients }\end{array}$ \\
\hline $1-3$ (minimal) & 16 \\
$4-8$ (mild) & 17 \\
$9-12$ (moderate) & 2 \\
$13-18$ (severe) & 0 \\
Levels of fibrosis (HAI-F score) & \\
0 (none) & 4 \\
1 (mild) & 25 \\
3 (severe) & 6 \\
4 (cirrhosis) & 0 \\
\hline
\end{tabular}

Histology was graded by the histologic activity index (HAI) according to the criteria of Knodell et al. ${ }^{12}$ The total HAI score is divided into two components: necroinflammation (HAI-NI) and fibrosis (HAI-F). The HAI-NI included three components (0-10, piecemeal necrosis; 0-4, lobular necrosis and inflammation; $0-4$, portal inflammation). The HAI-F was graded according to severity: 0 , absence of fibrosis; 1 , fibrous portal expansion; 3 , bridging fibrosis; 4 , cirrhosis.

\section{Discussion}

Virological markers (levels of serum HBV DNA), biochemical parameters (titers of serum ALT), and immunological markers (HBsAg, $\mathrm{HBeAg}$ and antibody to $\mathrm{HBeAg}$ ) are widely measured in patients with chronic hepatitis B to make a clinical diagnosis. In addition, levels of HBV DNA and ALT, and serostatus of $\mathrm{HBeAg}$ are used for: (1) selection of patients with antiviral therapy, (2) suggesting follow up without therapy, (2) assessment of therapeutic response and (4) ascertaining possibility of development of complications like cirrhosis of liver, hepatic decompensation and hepatocellular carcinoma. In fact, utility of levels of HBV DNA and ALT, serostatus of $\mathrm{HBeAg}$ in clinical diagnosis and management of these patients have been supported by several studies and also by global recommendations. ${ }^{8-10}$ However, others have shown that the levels of HBV DNA or ALT are not true surrogate markers of liver damages because several patients with low levels of HBV DNA have exhibited considerable liver damages in biopsy specimens. $^{2-7}$ However, liver biopsy is still regarded as the gold standard of liver damages in patients with chronic hepatitis.

The study that has been shown here has conclusively documented that some HBeAgnegative patients with undetectable HBV DNA and persistently normal ALT had moderate degrees of hepatic necroinflammation and severe hepatic fibrosis. Two of the 35 patients in this series had both moderate necroinflammation and severe hepatic fibrosis and they may develop liver cirrhosis in near future.

It is not clear why these patients had normal ALT for more than 1 year, although 2 of them had moderate hepatic necroinflammation. In fact, several patients with normal ALT and HBeAg negativity have been found to have severe hepatic necroinflammation and severe hepatic fibrosis and liver cirrhosis in Indian subcontinent, ${ }^{4,7}$ the underlying causes of which are to be explored in future. 
In addition to scientific importance, this study also has important public health implications. All professional liver organizations recommend treatment for patients with detectable or high HBV DNA and elevated ALT to block further progression of liver damage. ${ }^{8-10}$ Patients with undetectable HBV DNA with persistently normal ALT and HBeAg-negativity are neither recommended for therapy nor for liver biopsy. It is a fact that most of these asymptomatic patients reside in developing and resource-constrained countries of the world. Chronic HBV carrier is usually regarded as inactive $\mathrm{HBV}$ carrier if found to have undetectable HBV DNA, normal ALT and HBeAg negativity. However, as they express HBsAg, they are supposed to harbor HBV DNA in some body fluids or tissues, although they do not express detectable HBV DNA in the blood. The patient feels of being cured of $\mathrm{HBV}$ infection and donate blood and avoid safe delivery. But, they are infected with HBV and should not have these types of conceptions. These realities act as negative factors for containment of $\mathrm{HBV}$ in these countries.

It is also intriguing why two patients having moderate levels of hepatic inflammation and severe hepatic fibrosis did not show any subjective symptoms (Table III). In addition, they were negative for $\mathrm{HBeAg}$ with ALT values below upper level of normal $(<42 \mathrm{U} / \mathrm{L})$. They did not show any specific feature regarding clinical and other parameters. This normally raises concerns about utility of different surrogate markers of $\mathrm{HBV}$ for understanding of extent of liver damages. ${ }^{13}$ This study provides evidence that any patient with HBsAg-positivity should be properly assessed for different parameters of $\mathrm{HBV}$, even if they have normal ALT, HBeAg negativity, anti-HBe positivity and without subjective symptoms (Table III).

Table III: Profile of patient with hepatic inflammation and severe fibrosis

\begin{tabular}{lcc}
\hline Variables & Patient 1 & Patient 2 \\
\hline Age & 31 & 22 \\
Sex & Male & Female \\
Serum billirubin (mg/dL) & 0.6 & 0.5 \\
Alanine aminotransferase (IU/L) & 31 & 35 \\
Aspartate aminotransferase (IU/L) & 29 & 37 \\
Hemoglobulin (gm/dl) & 14.6 & 13.6 \\
Prothrombin time (sec) & 13.9 & 13.7 \\
Platelet count $\left(x 10^{9} / \mathrm{L}\right)$ & 180 & 340 \\
HBsAg & Positive & Positive \\
HBeAg & Negative & Negative \\
Anti HBeAg & Positive & positive \\
Anti-HCV & Negative & Negative \\
HBV-DNA(PCR) & Negative & Negative \\
Ultrasonography & Normal & Normal \\
Histology activity index & Moderate & Moderate \\
Fibrosis & Severe & Severe \\
\hline
\end{tabular}

It is agreed that there are some limitations of this study. The sample size was small and liver biopsy was conducted only once. In fact, this is a pilot study and process to start a large study to elucidate pathological status of so-called inactive HBV carriers and patients with undetectable HBV DNA is under active consideration. Also, virological analyses and genome analyses have not been conducted in this study.

However, the data of this pilot study can be used for develop insights about pathological status of different chronic HBV carriers. It is believed do believe that more studies would be accomplished about assessment of liver biopsy in undetectable HBV DNA patients that may be useful for planning containment and therapy of $\mathrm{HBV}$ infection in global context.

\section{Reference}

1. Iloeje UH, Yang HI, Su J, Jen CL, You SL, Chen CJ. Risk Evaluation of Viral Load Elevation and Associated Liver Disease/Cancer-In HBV (the REVEAL-HBV) Study Group. Predicting cirrhosis risk based on the level of circulating hepatitis B viral load. Gastroenterology 2006; 130: 678-86.

2. Chen CJ, Yang HI, Su J, Jen CL, You SL, Lu SN, Huang GT, Iloeje UH, REVEAL-HBV Study Group. Risk of hepatocellular carcinoma across a biological gradient of serum hepatitis B virus DNA level. JAMA 2006; 295: 65-73.

3. Andreani T, Serfaty L, Poupon R, Chazouilleres O. Need to strictly define hepatitis B virus immunotolerant patients to avoid unnecessary liver biopsy. Gastroenterology 2008; 135: 2155-56.

4. Kumar M, Sarin SK, Hissar S, Pande C, Sakhuja P, Sharma BC, Chauhan R, Bose S. Virologic and histologic features of chronic hepatitis B virus-infected asymptomatic patients with persistently normal ALT. Gastroenterology 2008; 134:1376-84.

5. Lai M, Hyatt BJ, Nasser I, Curry M, Afdhal NH. The clinical significance of persistently normal ALT in chronic hepatitis B infection. J Hepatol 2007; 47: 760-67.

6. Chun YK, Kim JY, Woo HJ, Oh SM, Kang I, Ha J, Kim SS. No significant correlation exists between core promoter mutations, viral replication, and liver damage in chronic hepatitis B infection. Hepatology 2000; 32:1154-1162.

7. Al-Mahtab M, Rahman S, Akbar SM, Kamal M, Khan MS. Clinical use of liver biopsy for the diagnosis and management of inactive and asymptomatic hepatitis B virus carriers in Bangladesh. J Med Virol 2010; 82: 1350-54.

8. Lok AS and McMahon BJ. AASLD Guidelines Chronic hepatitis B; Update 2009; Hepatology 2009; 50:1-36. 
9. European Association for the Study of the Liver. EASL clinical practice guidelines; Management of chronic hepatitis B. J Hepatol 2009; 50: 227-42.

10. Liaw YF, Leung N, Kao JH, Piratvisuth T, Gane E, Han KH, Guan R, Lau GK, Locarnini S. Chronic Hepatitis B Guideline Working Party of the AsianPacific Association for the Study of the Liver. AsianPacific consensus statement on the management of chronic hepatitis B: a 2008 update. Hepatol Int 2008; $22 ; 262-83$.

11. Shiha G, Sarin SK, Ibrahim AE, Omata M, Kumar A, Lesmana LA, et al. Liver fibrosis: consensus recommendations of the Asian Pacific Association for the Study of the Liver (APASL). Hepatol Int 2009; 3: 323-33.

12. Knodell RG, Ishak KG, Black WC, Chen TS, Craig R, Kaplowitz N, Kiernan TW, Wollman J. Formulation and application of a numerical scoring system for assessing histological activity in asymptomatic chronic active hepatitis. Hepatology 1981; 1: 431-35.

13. Akbar SM, Al-Mahtab M, Hiasa Y. Future aspects of therapy for hepatitis B virus infection: value of surrogate markers, innovative therapy, and global collaboration. J Gastroenterol 2011; 46: 717-23. 